\title{
Determinació experimental del camp magnètic terrestre
}

\author{
David Campos Abad \\ IES Ximén d'Urrea de l'Alcora (Castelló)
}

La majoria de la gent -i els nostres alumnes també- sap que una brúixola s'orienta vers el nord o que els pols iguals dels imants es repel/leixen i els distints s'atrauen, però sovint poca cosa més. Amb les experiències que mostrem es pretén aprofundir en aquests fenòmens per comprendre un poc millor quina és la física que s'hi amaga darrere.

Paraules clau: Terra, brúixola, magnetisme

\section{OBJECTIU}

- Construcció d'una brúixola casolana i visualització de camps magnètics generats per conductors

- Determinació experimental del camp magnètic terrestre i comprovació teòrica
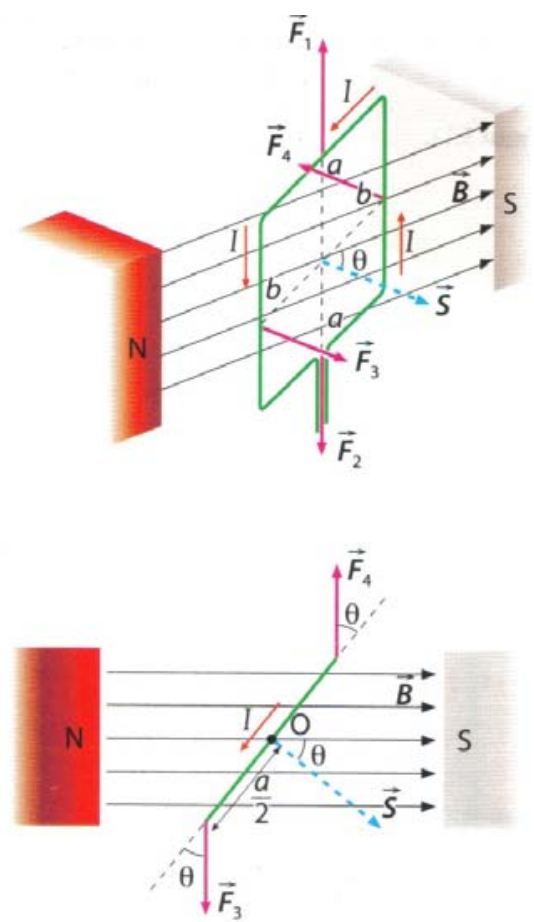

Figura 1. Espira rectangular situada a l'interior d'un camp magnètic uniforme

\section{INTRODUCCIÓ}

\section{Moment d'un parell de forces i moment magnètic}

Imaginem la situació d'una espira rectangular situada dins d'un camp magnètic uniforme (fig. 1).

Aplicant la llei de Laplace comprovarem que apareixen quatre forces sobre els seus quatre costats. Sobre el costat superior i l'inferior apareixen dues forces $\left(\boldsymbol{F}_{1}\right.$ i $\left.\boldsymbol{F}_{2}\right)$, que són iguals en direcció $\mathrm{i}$ mòdul però de sentit oposat. Per tant, és cancel-laran mútuament. A més a més, el seu moment de forces és zero, ja que els vectors de posició respecte del centre de masses, $\boldsymbol{r}_{1}$ i $\boldsymbol{r}_{2}$, són paral·lels a les forces.

Per un altre costat tenim que les forces $\boldsymbol{F}_{3}$ i $\boldsymbol{F}_{4}$ també són iguals en direcció i mòdul i de sentit oposat. Però en aquest cas no són paral-lels a $\boldsymbol{r}_{3}$ i $\boldsymbol{r}_{4}$ motiu pel qual presentaran un moment de forces $\vec{\tau}$ sobre l'espira que la farà girar:

$$
\vec{\tau}=\vec{r}_{3} \times \vec{F}_{3}+\vec{r}_{4} \times \vec{F}_{4}
$$

Com que $r_{3}=r_{4}=a / 2$ :

$$
\tau=\frac{a}{2} F_{3} \sin \theta+\frac{a}{2} F_{4} \sin \theta
$$

i sent $F_{3}=F_{4}$ :

$$
\tau=a F \sin \theta
$$


Aplicant la llei de Laplace i tenint en compte que els costats b són sempre perpendiculars a $B$ :

$$
F=I b B
$$

Així doncs:

$$
\tau=I b B a \sin \theta
$$

Com que $a \cdot b=S$ :

$$
\tau=I S B \sin \theta
$$

$\theta$ és l'angle que formen $\vec{S}$ i $\vec{B}$. Per tant:

$$
\vec{\tau}=I \vec{S} \times \vec{B}
$$

El moment magnètic $\vec{\mu}$ (fig. 2) es defineix com:

$$
\vec{\mu}=I \vec{S}
$$

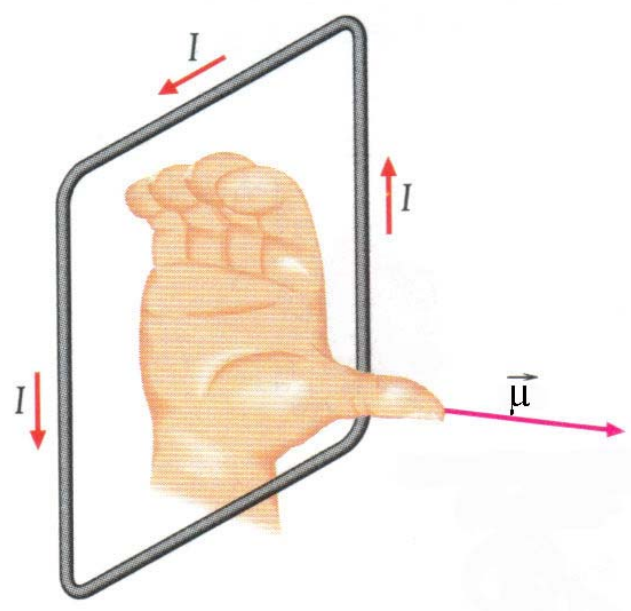

Figura 2. Determinació de la direcció i sentit del moment magnètic creat a l'interior d'una espira.

Per tant, podem expressar el moment de forces com el producte vectorial del moment magnètic de l'espira i el camp magnètic extern:

$$
\vec{\tau}=\vec{\mu} \times \vec{B}
$$

A partir d'aquesta fórmula, podem deduir que l'espira girarà fins que el moment magnètic sigui paral-lel al camp magnètic, moment en el qual el moment de forces serà nul.

Aquesta deducció és extensible a la matèria: el seu comportament magnètic és degut al moment magnètic orbital dels electrons (moviment orbital) i al moment magnètic d'espín (propietat intrínseca de l'electró, clàssicament atribuït a un moviment de rotació de l'electró sobre un dels seus diàmetres).

\section{Comportaments magnètics de les substàncies}

La matèria presenta diferents formes de comportament magnètic. A continuació parlarem del paramagnetisme i el diamagnetisme, i també del ferromagnetisme com a cas concret de paramagnetisme.

El paramagnetisme (fig. 3a) és causat, generalment, per àtoms, ions o molècules que presenten electrons desaparellats. Aquesta situació ocasiona que presenten moments magnètics permanents en absència d'un camp magnètic extern. Com que la interacció entre ells és dèbil, la tendència d'un camp magnètic extern a alinear-los paral-lelament es veu contrarestada per l'agitació tèrmica (depèn de la temperatura i de la intensitat del camp, però és menuda).

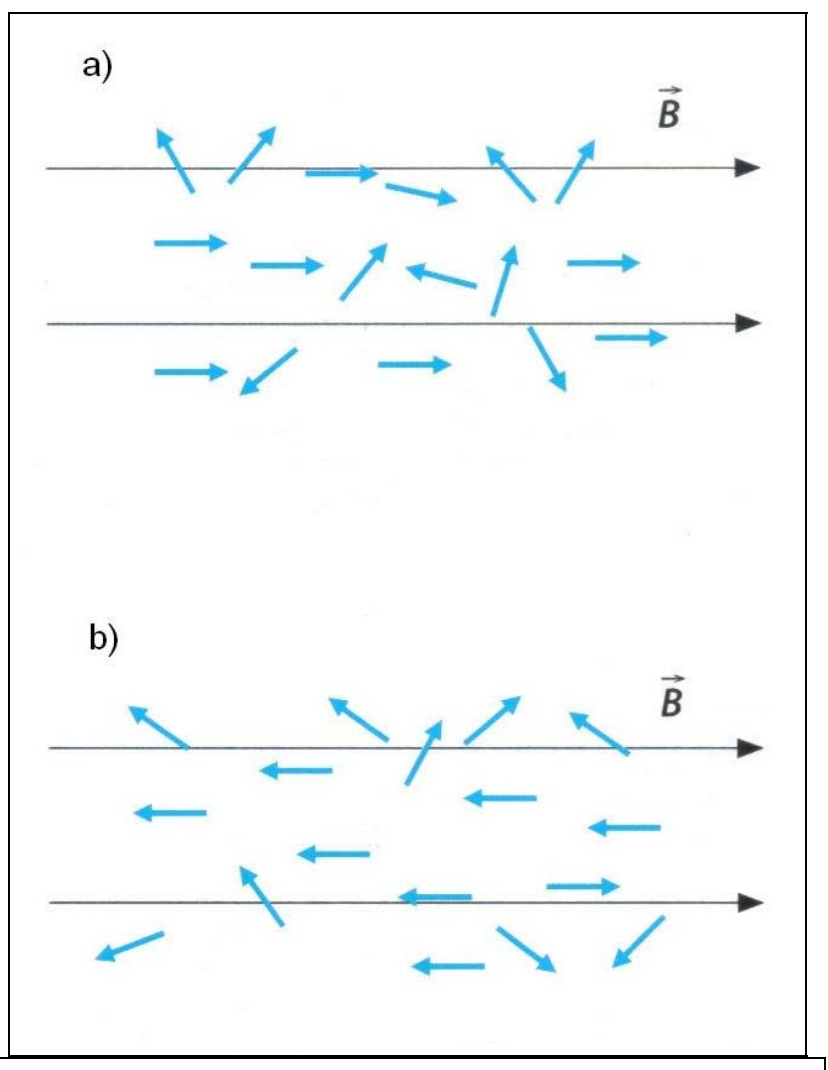

Figura 3. a) Paramagnetisme. b) Diamagnetisme.

El diamagnetisme (fig. 3b) el produeixen les capes tancades de les substàncies. Aquestes tenen cancel-lats els moments magnètics d'espín i orbitals dels electrons, motiu pel qual el seu moment 
magnètic resultant és zero. En presència d'un camp magnètic extern es produeix una lleugera inclinació dels plànols orbitals que genera un lleuger moment magnètic orbital que s'oposa al camp. És una conseqüència de la llei de Lenz de l'electromagnetisme (a la seua vegada conseqüència de la llei d'acció i reacció de Newton), i és per això que el presenten totes les substàncies. Així doncs, el paramagnetisme observat en una substància és lleugerament inferior al real, ja que una part és cancel·lada pel diamagnetisme.

$\mathrm{Hi}$ ha altres formes de paramagnetisme complexes, en les que entren en joc altres factors (quàntics). En concret, parlarem del ferromagnetisme. Perquè aquest tinga lloc, a part de la condició d'electrons desaparellats del paramagnetisme, s'ha de produir una interacció entre els moments magnètics dels electrons que els alineï paral-lelament (amb la mateixa direcció i sentit), fins i tot en absència de camps magnètics externs. Aquesta interacció fa que els moments magnètics individuals se sumen $\mathrm{i}$ no hi hagi cap tipus de cancel·lació, com ocorre quan estan distribuïts de forma aleatòria. Tal condició només pot tenir lloc en determinats àtoms (per grandària), ja que, si són grans, els electrons interaccionen molt poc, i si són menuts, els àtoms s'emparellen i alineen els moments magnètics antiparal-lelament, cancel-lant el total. L'alineació es produeix en zones microscòpiques, anomenades dominis magnètics, i es poden caracteritzar per un moment magnètic que representa el domini. Cada domini és independent i està distribuït a l'atzar (fig. 4), i per això el moment magnètic total del material és zero doncs s'anul·len mútuament.

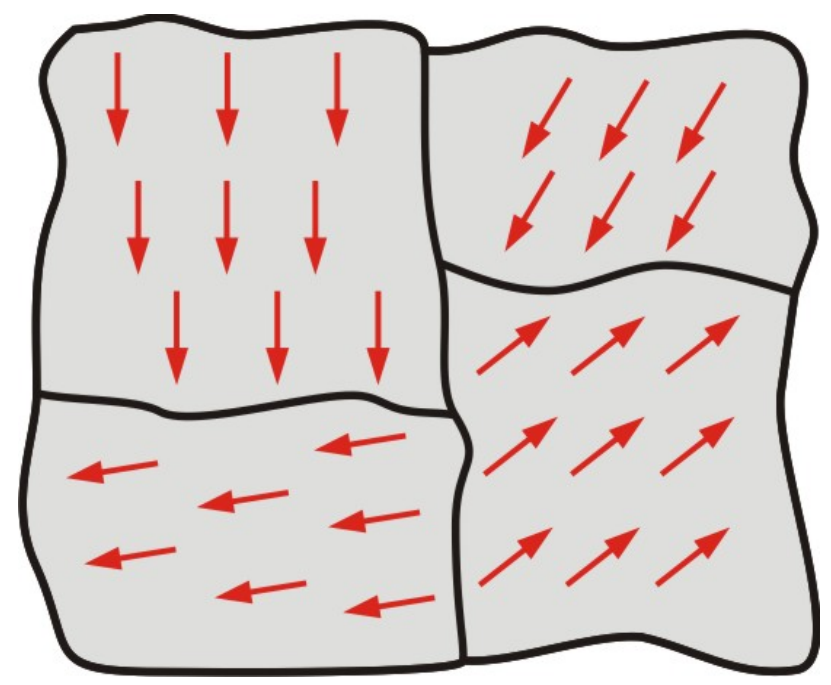

Figura 4. Diversos dominis magnètics en un material ferromagnètic.
En presència de camps magnètics externs menuts i a temperatures considerables (com les ambientals), es poden trencar les parets dels dominis $i$ orientar-los tots en el mateix sentit del camp extern, aconseguint camps magnètics del material elevats que poden continuar, fins i tot, quan cessa el camp magnètic extern. Existeix una temperatura (temperatura de Curie), a partir de la qual l'agitació magnètica trenca aquesta interacció, de forma que el material passa a comportar-se com una substància paramagnètica simple.

El ferromagnetisme es presenta en el ferro, cobalt, níquel, gadolini, disprosi, alguns aliatges d'altres elements químics i poques substàncies més.

Les brúixoles estan formades per agulles de materials ferromagnètics imantades que poden girar amb facilitat en presència d'un camp extern. Podem representar-les amb el vector del seu moment magnètic total. Aquest vector, i per tant l'agulla, girarà fins a posar-se paral-lelament al camp magnètic terrestre.

El nostre planeta es comporta com un imant permanent a causa de l'elevat contingut en ferro $\mathrm{i}$ níquel del nucli terrestre, la seva elevada temperatura i l'efecte Coriolis.

\section{Construcció d'una brúixola casolana}

\section{Material}

- Dues agulles

- Cola

- Botó automàtic

- Cartró

- Xinxeta

- Estisores

\section{Orientacions pel professorat}

Aquesta experiència és adequada per a qualsevol curs. A segon de batxillerat els alumnes tindran una comprensió didàctica completa, mentre que a l'ESO ens conformarem amb explicar els continguts més superficialment. Amb una sessió de classe en tenim prou.

\section{Procediment experimental: imantació de les agulles}

Agafarem un imant de laboratori i comprovarem quin és el pol nord i quin el sud (per exemple, apropant-lo a una brúixola comercial). Seguidament, posarem les agulles en vertical i donarem uns copets amb l'imant (el pol sud ha d'impactar amb la punta 
afilada de la agulla). D'aquesta manera trencarem els dominis de l'agulla i es col·locaran tots paral·lels al camp magnètic, aconseguint dos imants permanents amb pol nord a la punta afilada de l'agulla.

\section{Acoblament de les peces}

Pegarem les agulles amb cola a la part del botó amb punta (l'altra part del botó no la necessitem) (fig. 5).

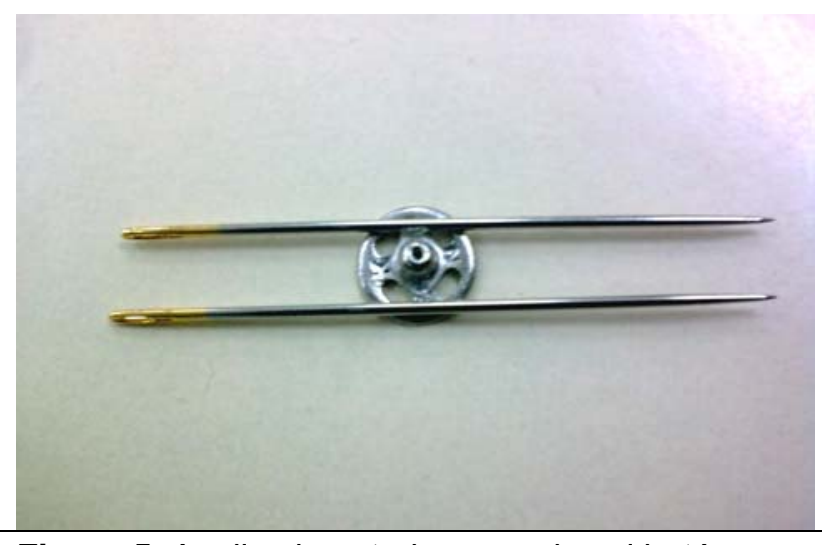

Figura 5. Agulles imantades pegades al botó.

Deixarem uns minuts perquè s'enganxi. Després retallarem dos trossets de cartolina: l'un per fer la punta i l'altre la cua. Seguidament, els pegarem a les agulles i posarem aquesta estructura sobre la xinxeta. Si la part mòbil està desequilibrada, retallarem la punta o la cua de la fletxa fins que aconseguim l'equilibri (fig. 6).

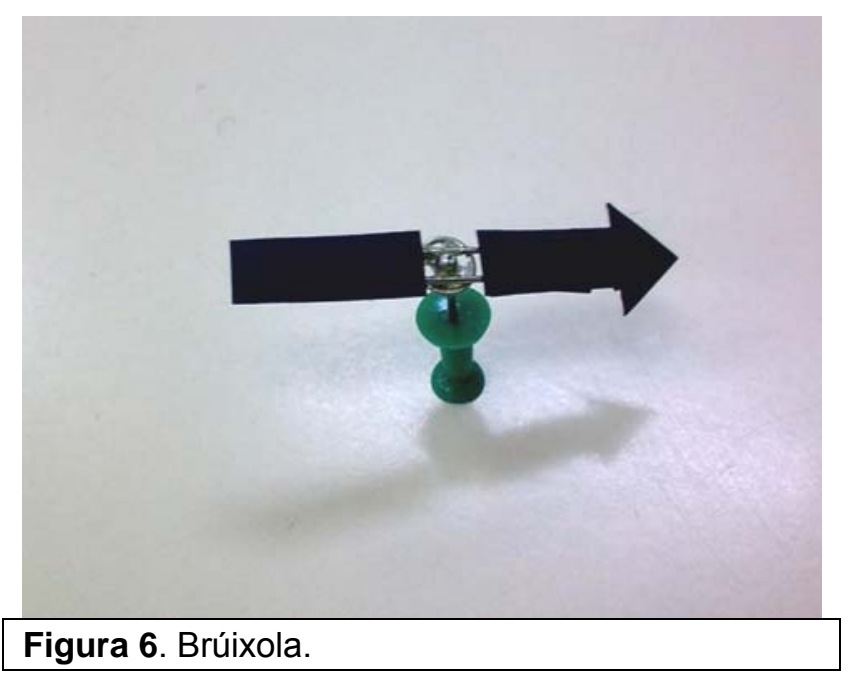

\section{Buscant el nord}

Finalment comprovarem que marca el nord (ajudem-nos d'una brúixola de compra), que té poc fregament i bona facilitat de gir (donem-li un copet). És important que no hi hagi cap material de ferro a prop, ja que, el seu camp magnètic hi interferirà.

\section{Resultats}

Una vegada construïdes les brúixoles amb els nostres alumnes, podem ficar-les totes al voltant d'una espira, bobina o conductor rectilini pel que circuli un corrent per veure les línies de camp. Aquesta última és l'experiència d'Oersted. També ho podem fer amb un imant permanent. Després podem canviar les connexions i veure com les brúixoles s'orienten canviant de sentit. En la mateixa línia es pot augmentar el voltatge i veure com la força magnètica s'hi fa més gran.

\section{Determinació experimental del camp magnètic terrestre}

\section{Material}

- Conjunt d'espires (8)

- Polímetre

- Generador de corrent continu

- Cables

- Resistència (30 o $40 \Omega$ )

- Brúixola

- Dos suports, dues pinces i dues nous

- Limbe graduat per a angles

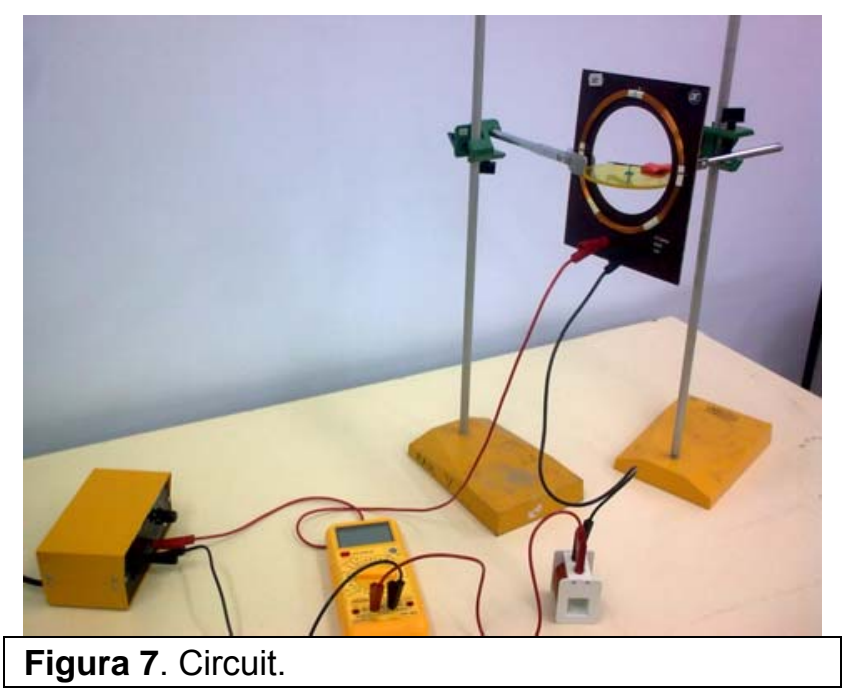




\section{Orientacions pel professorat}

Aquesta experiència és adequada per al batxillerat. Si la fem a segon després de veure magnetisme, ens ajudarà a reforçar conceptes. Si la fem a primer, podria servir com una introducció. Amb una sessió de classe en tindrem prou.

\section{Procediment experimental: muntatge del circuit}

Farem el muntatge del circuit (fig. 7). Els limbes graduats van amb una agulla imantada, però solen ser defectuoses, de forma que l'hem treta i hi hem afegit la nostra brúixola casolana (la xinxeta coincideix exactament amb el foradet que hi ha al mig del limbe). També cal dir que s'ha utilitzat una bobina de $42 \Omega$ com a resistència, en comptes d'una resistència tal qual (per comoditat).

Com que la brúixola marcarà el nord magnètic, haurem d'anar girant els dos suports de forma que marqui $0^{\circ}$ a la placa graduada (fig. 8).

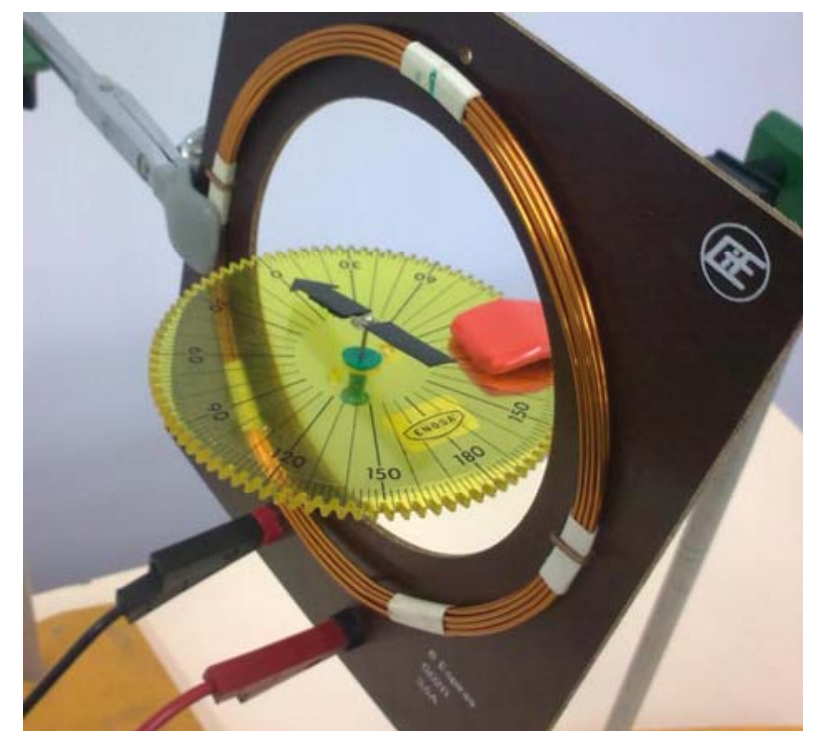

Figura 8. Brúixola al centre d'un conjunt d'espires.

A més, és molt important que estiga d'allò més horitzontal possible, ben centrada i que coincideixi tot el que puguem amb un diàmetre de les espires.

\section{Enregistrament de dades}

La primera cosa que farem serà posar el polímetre en la funció d'amperímetre en corrent contínua (amb un màxim de $200 \mathrm{~mA}$ ). També necessitem el nombre d'espires i el diàmetre de les espires. En aquest moment, engegarem el generador a $4,5 \mathrm{~V}$, agafarem les dades de la intensitat de cor- rent i mesurarem l'angle desviat per l'agulla. Repetirem les mesures per a diferents voltatges progressivament més grans.

\section{Resultats}

Inicialment, és a dir quan no circula corrent per l'espira, la brúixola està situada en la mateixa direcció i sentit que el camp magnètic terrestre (indica el nord). Recordem que aquesta direcció ha de coincidir amb un dels diàmetres de les espires. Quan engeguem el generador les espires creen un camp magnètic que és perpendicular al seu plànol i, per tant, al camp magnètic terrestre. Així doncs, la brúixola s'orientarà en la direcció del camp resultant (suma vectorial del camp magnètic terrestre i el generat per les espires). El camp magnètic en el centre d'un conjunt d'espires (que és on ha d'estar la brúixola) ve donat per la següent fórmula:

$$
B=N \frac{\mu_{0} I}{2 R}
$$

on $\mu_{0}=4 \pi \cdot 10^{-7} \mathrm{~N} \cdot \mathrm{A}^{-2}$ és la permeabilitat del buit, semblant a la de l'aire,

$I$ (A) és la intensitat de corrent,

$R(\mathrm{~m})$ és el radi de les espires, calculat a partir del diàmetre,

$B(T)$ és el camp magnètic al centre de les espires,

i $N$ és el nombre d'espires.

Amb el camp magnètic al centre de les espires $i$ l'angle que ha girat la brúixola, podrem calcular el camp magnètic terrestre:

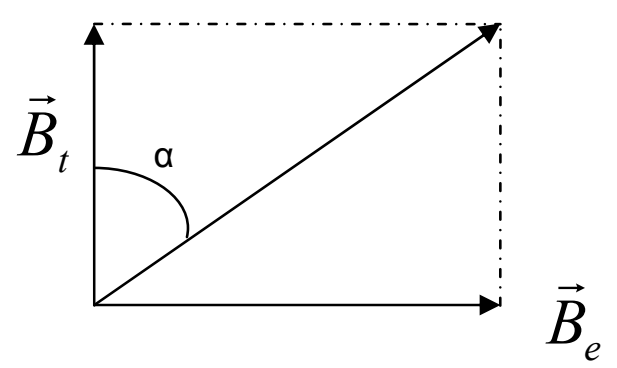

Per tant:

$$
\operatorname{tag} \alpha=\frac{B_{e}}{B_{t}}
$$

Calculem $B_{t}$ per a diferents angles i voltatges. Finalment, en farem la mitjana aritmètica. 


\section{Comprovació teòrica de la nostra dada experimental}

Hi ha una calculadora online del NOAA (National Oceanic and Atmospheric Administration) dels Estats Units que ens calcula el camp magnètic terrestre si li introduïm la data, les coordenades terrestres (latitud i longitud) i l'altitud.

Podem seleccionar un país i una ciutat (ens introduirà les coordenades directament) 0 , si volem més exactitud, haurem de buscar les coordenades del lloc on hem fet l'experiment i ficar-les. Aquesta tasca la podem realitzar senzillament amb programes de descàrrega gratuïta com Google Earth.

El camp magnètic no és constant en tota la superfície terrestre (podem visualitzar-ho canviant de país). A més, té una component nord, una component est o oest i una component vertical (amunt $o$ avall). Recordem que el nord magnètic no coincideix exactament amb el nord geogràfic. La nostra brúixola està en posició horitzontal, per tant, només marcarà la component horitzontal del camp (suma vectorial de la component nord més l'est o oest); però no la vertical.

És una experiència sorprenent perquè, si no hem comés cap error, el valor experimental s'aproxima molt al teòric.

\section{BIBLIOGRAFIA}

TIPLER, Paul (2000). Física para la ciencia y la tecnología. $4^{a}$ ed. Barcelona: Reverté. 1412 págs.

PETRUCCI, Ralph H. ; HARWOOD, William S. ; HERRING, F. Geoffrey (2003). Química General. $8^{a}$ ed. Madrid: Prentice Hall. 1288 págs.

COTTON, F. Albert ; WILKINSON, Geoffrey (1993). Química inorgànica avanzada. $4^{a}$ ed. Mexico: Limusa. 1669 págs.

BARRIO, Jorge (2000). Física $2^{\circ}$ Bachillerato. Navarra: Oxford. 419 págs. 